\title{
La tradición maliense en Recas: las funciones sociales de un griot bambara
}

\author{
The Malian tradition \\ in Recas: Social \\ roles of a Bambara griot
}

\section{VICENTE ENRIQUE MONTES NOGALES*}

Resumen: Malí es uno de los países de África occidental donde la tradición ha perdido vigor con motivo de grandes transformaciones sociales. El éxodo de las aldeas y la inmigración han originado que los griots, uno de los grupos sociales que en mayor medida dependía de las costumbres que se conservaban por la transmisión de padres a hijos, se hayan visto obligados a realizar nuevas labores para asegurar su sustento y adaptar sus funciones a los cambios. Mi intención es ilustrar cómo esta adecuación a nuevas circunstancias se produce en Recas, un municipio de la provincia española de Toledo donde reside una importante comunidad maliense.

Palabras clave: maliense; Recas; griot; tradición; inmigración.

Abstract: Mali is one of the West African countries where tradition has lost its relevance due to sweeping social changes. Rural exodus and immigration have obliged griots, a social group heavily dependent

Recepción: 20 de octubre de 2017. / Aceptación: 29 de agosto de 2018.

* Universidad de Oviedo, montesvicente@uniovi.es 
on customs being preserved as they are passed down through the generations, to take on new activities to earn their living and to adapt their roles to new circumstances. I intend to illustrate how this adjustment takes place in Recas, a municipality in the province of Toledo (Spain), home of an important Malian community.

Keywords: Malian; Recas; griot; tradition; immigration.

\section{Introducción}

En el municipio de Recas, en Castilla-La Mancha (España), conviven individuos de más de cuarenta nacionalidades. Conforme a los datos presentados por el Instituto Nacional de Estadística (INE, 2016a), el municipio contaba en 2016 con 4309 habitantes. En su ayuntamiento, en agosto de ese año, me informaron que 653 de las personas censadas eran malienses. Huir de la pobreza, evitar el desempleo y buscar una oportunidad laboral en alguna de las empresas allí situadas o en las plantaciones son las razones que han atraído paulatinamente, desde hace casi tres décadas, a la mayor parte de los africanos que residen en esa localidad.

El bambara Djeliba Souleymane acude a Recas cada fin de semana. Forma parte de una minoría de africanos cuyas ocupaciones habituales están estrechamente vinculadas a la palabra y al poder que ésta ejerce sobre los demás miembros de la comunidad en la que cumple sus funciones. Puede sorprender que el pueblo en el que lleva a efecto un cometido que ya correspondía a sus antepasados se encuentre en España, lejos de Malí, el país del que procede. Djeliba no es un nombre, hace referencia a la ascendencia o el linaje de unos individuos, al grupo social al que pertenecen por nacimiento, que implica que desarrollen determinadas tareas y que presten servicios a otros estamentos. Djeliba es traducido a menudo como 'gran griot', es decir, gran profesional de la palabra (Cissé y Kamissoko, 1988, p. 3; Camara, 1992, p. 120). Los malinké, que constituyen un grupo de población importante en Guinea y minoritario, pero relevante, en el sur de Senegal, en el sudoeste de Malí y en el noroeste de Costa de Marfil, denominan jèlibá al griot que toca el kòní o ngoni, una mandolina o banyo de cuatro a seis cuerdas, y que tiene gran facilidad de palabra (Camara, 1992, p. 113). 
Para comprender la particular relación que Djeliba Souleymane mantiene con otros subsaharianos que viven en España, como Amadou Traoré, uno de mis informantes, son necesarios algunos datos de la sociedad maliense tradicional -que, incluso a miles de kilómetros, todavía condiciona a la presente-, de los bambara, del valor de la palabra oral y de los cambios que la inmigración ha originado en el modo de vida de los griots.

Este artículo es resultado de mis investigaciones en Recas (Toledo, España), de las conversaciones mantenidas con algunos miembros de la comunidad maliense, sobre todo con Djeliba Souleymane, el principal griot de ese pueblo, desde la primavera de 2015 hasta el verano de 2017, y del estudio de las funciones de los narradores de África occidental. Las entrevistas realizadas a estos africanos fueron grabadas. Amadou Traoré, con quien Djeliba mantiene una particular relación basada en jerarquías sólidamente establecidas en el pasado, me ayudó a aclarar mis dudas cuando no lograba comprender las explicaciones de Djeliba.

\section{La sociedad maliense: de la tradición a la modernidad}

En el territorio que hoy conocemos como Malí conviven desde hace siglos diferentes etnias, como la bambara, cuya mayor parte se encuentra también en Burkina Faso, Guinea y Senegal; la malinké y la soninké, que habitan principalmente las regiones limítrofes de Malí, Mauritania y Senegal; la fulani, presente en unos veinte países de África occidental y central; la senufo, comunidad repartida asimismo en el oeste de Burkina Faso y el norte de Costa de Marfil; la songhai ${ }^{1}$ y la tuareg, que residen, además, en Níger, Argelia, Libia y Burkina Faso; y la dogón. ${ }^{2}$ Aunque poseen características que las diferencian, comparten numerosos rasgos. La estructura social de los diversos reinos que componían Malí se basaba, entre otros factores, en una sólida

\footnotetext{
${ }^{1}$ Se conocen diferentes grafías para este término; entre las más frecuentes encontramos songhay, songhaï, songay y songai. Los songhai constituyen un grupo étnico importante en Níger y Malí. Mopti.

${ }^{2}$ La mayoría de los dogón se encuentra en la región central maliense llamada
} 
jerarquía en la que los horon, hombres libres o nobles, ocupaban una posición superior a los siervos y a los hombres de casta o artesanos, entre los que destacaban los herreros, los curtidores, los marroquineros y los trabajadores de la madera. Los cazadores eran especialmente respetados porque, aparte del mérito que se concedía a la cinegética, se les atribuían dotes mágicas y de videncia. La organización social se apoyaba al menos en una triple división, originada por la disposición de las castas, la edad y el sexo. A algunos individuos les correspondía competir para demostrar su retórica y custodiar el conocimiento transmitido de generación en generación, eran los artesanos del Verbo, designados en numerosas ocasiones como griots (Chamorro, 1993, p. 228). Hampâté Bâ (1982, p. 208) diferencia tres clases de griots en aquellos países de África occidental donde existe esta figura, en función principalmente de su saber: los músicos; los embajadores y los artesanos, y los genealogistas, los historiadores y los poetas. Otros estudiosos permiten conocer en profundidad las variedades de griots (Seydou, 1976, p. 7; Chevrier, 1990, p. 199; Kesteloot y Dieng, 1997, p. 54).

La palabra tenía gran protagonismo en las sociedades subsaharianas, por lo que convenía averiguar desde temprano los beneficios y los daños que suponía emplearla correctamente o con imprudencia. La palabra era concebida como una lanza que, una vez arrojada, no retorna, así que era preferible reflexionar antes de emitirla, pues podía desencadenar graves consecuencias. Mediante ella se adquiría prestigio porque demostraba la sabiduría del orador. Si cualquier miembro de la comunidad podía aspirar a hacer uso de la palabra para argumentar, persuadir o entretener, algunos individuos hacían de ella una herramienta de trabajo, ya que de su buen empleo dependía su sustento. Además, al haberla heredado de sus antepasados, debían protegerla.

La importancia de la palabra es tal que tradicionalmente los varones bambara o fulani no tenían derecho a emplearla públicamente hasta haber alcanzado la edad de 43 años. Antes, la comunidad podía autorizarles a servirse de ella, pero para que dieran muestra de su evolución personal (Hampâté Bâ, 1972, p. 13). La palabra rige la vida de los mandinga, que integran a los bambara, los diola (o diula) y los malinké, y cuyo territorio 
incluye una extensa zona de Malí, el nordeste de Guinea, el norte de Costa de Marfil, el sudoeste de Burkina Faso, una fracción de Gambia, una parte del este de Senegal y una pequeña porción de Liberia (Derive y Dumestre, 1999, pp. 9-10). ${ }^{3} \mathrm{La}$ palabra regula su actividad social, sus enfermedades y hasta su muerte: "Dominando la palabra, se considera que se controla todo en la vida. Está en la base de la vida y en la continuación de la vida" (Cherif, 2005, p. 40). Para los mandinga, la palabra pronunciada, o kuma, posee un poder, o nyama, que puede ocasionar daño si su uso no es correcto; por ello, el que no conozca el koro, o sentido de la palabra, ha de evitar su empleo (Jansen, 2001, pp. 158-159).

Los bambara, etnia a la que pertenecen nuestros informantes, son originarios de los montes Mandinga y poco a poco se dispersaron hacia el centro de Malí (Kesteloot, 1993, pp. 3-4). Según Viviana Pâques (2005, p. 80), la población bambara alcanza el millón. Los bambara residen principalmente en Malí (sobre todo en Segu, Bamako y Bougouni), Burkina Faso, Guinea y Senegal. Se sabe que la disposición de la sociedad bambara tradicional no difería de la mencionada anteriormente. El trabajo de la tierra correspondía a los hombres libres, mientras que el de la artesanía, a los nyamankala (o ñàmàkálâ). Entre estos últimos distinguimos de nuevo a los que ejercitaban el oficio del cobre y del hierro, a los que trabajaban la piel o la

\footnotetext{
${ }^{3}$ En ocasiones hallamos las grafías manding, mandé y manden, entre otras. Con la palabra manding, Derive y Dumestre $(1999$, p. 9) designan el territorio mandinga. Recuerdan al lector que fueron principalmente los lingüistas los que realizaron la distinción entre "mandé" y "mandinga". Para establecer las fronteras del territorio indicado se basan en dos criterios: lingüísticos y culturales. Jansen (2001, p. 11) prefiere no mencionar la delimitación exacta de la cultura mandinga porque el resultado sería muy impreciso. Cuando evoca el nombre mandé, se refiere a la región en la que la mayor parte de la población afirma descender de Sundiata, el emperador mandinga, o de alguno de sus colaboradores. Delafosse diferenciaba en la familia mandé del territorio de la administración civil del Alto Senegal y Níger tres grupos: norte, centro y sur. En el grupo del centro incluía cinco pueblos: "los kdgoro, los banmana (o bambara, incluida la casta de los somono), los khassonkè, los malinké (o mandinga) y los fulanké" (Delafosse, 1912, p. 113). Pâques (2005, p. 2) lamenta que la clasificación de Delafosse confunda a menudo la lengua con los rasgos físicos. Camara (1992, pp. 17-18) destaca los siguientes grupos étnicos entre los mandé: soninké, bambara, diola, bobo, bozo, bisa, kuranko, toma, mendé, tura y dane, etcétera. Según este autor, mandinga es un término creado a partir de mandenká (gente del Mandé) y comprende a los bambara, los diola y los malinké.
} 
madera, y a los djeli ${ }^{4}$ o griots, cuyas actividades se heredaban de padres a hijos.

Los estudiosos coinciden en afirmar que en el pasado la religión ha condicionado toda actividad desarrollada por los bambara. Pâques (2005, p. 80) insiste en que "determina la vida social, política, artística e incluso económica del país”. Germaine Dieterlen (1988) había demostrado que el sistema cosmogónico y metafísico de los bambara es riquísimo. El catolicismo no impidió el triunfo del islam, que supo ganar adeptos con el paso de los años, pero debemos hablar de un sincretismo religioso derivado de la combinación de animismo e islam.

Si la sociedad bambara, al igual que las demás sociedades de África occidental, conoció radicales transformaciones con motivo de la colonización, las últimas décadas todavía han supuesto nuevos cambios. Las ciudades atraen a los jóvenes de las aldeas y los alejan de la tradición, en particular de la transmitida por los griots, que gozan de mayor reconocimiento y que residen en algunos pueblos conocidos por el número de tradicionistas que reúnen. Abimbola (1990) denunciaba, a finales del siglo xx, el impacto devastador de la modernización o desarrollo sobre la cultura tradicional africana. Vincent Zanetti lamenta que la música mandinga esté desapareciendo paulatinamente como consecuencia de la emigración de los artistas (Blit, 2009).

El desinterés de los jóvenes por la tradición y el éxodo rural han provocado, según Zanetti, que la tradición se desvanezca allí donde ha surgido, ya que la emigración es mayor en el entorno rural (Organización Internacional para las Migraciones, 2013). Ni siquiera las instituciones son garantía de la protección de las costumbres y las doctrinas conservadas durante siglos. Bouju (1995) presenta algunos ejemplos de asociaciones que, aunque se erigen en protectoras de la tradición dogón en $\mathrm{Ba}-$ mako, no la dan a conocer con rigor, aun cuando algunos de sus miembros son dogón. Por otra parte, la estructura del trabajo basada en la artesanía local se ve suplantada por la importación y la industria, que si bien no se puede considerar desarrollada, sí ha instaurado la organización económica europea. Los terrenos

${ }^{4}$ Encontramos diferentes grafías para referirse a estos bardos; por ejemplo: dyeli, jèlí y jàlí. 
y los huertos individuales ganan adeptos y dejan en un segundo lugar los familiares, como consecuencia del individualismo que cada vez cobra mayor protagonismo en África. Conviven, de este modo, dos formas de organización económica, como afirma Pâques (2005, p. 88): "Por un lado, la organización indígena tradicional y artesanal; por otro, la organización europea que ha quebrado la antigua sociedad y ha orientado la economía local del país hacia la economía internacional".

Además, un porcentaje elevado de malienses tiene que hacer frente al grave problema que supone la pobreza. Malí es uno de los países más pobres del mundo (Diarra y Cissé, 2003; PNUD, 2016; Banco Mundial, 2016), hecho que, junto con el desempleo y el crecimiento demográfico, origina emigración. Una parte importante de su población vive en Bamako y otra, también significativa, en países vecinos, como Costa de Marfil o Senegal. Las condiciones de vida, sobre todo en el entorno rural, están estrechamente vinculadas a las condiciones climáticas (Ministère de l'Environnement et de l'Assainissement, 2011), por lo que algunas sequías, como las producidas en los años 1972-1973 y 1983-1984, han provocado flujos migratorios sustanciales, tanto internos como hacia otros países, entre ellos Francia (Ballo, 2009, pp. 60-61). En la década de 1990, el medio rural continuó siendo el principal expulsor de emigrantes (Ballo, 2009; Diarra et al., 1996) y 62\% del flujo migratorio se dirigió al extranjero. De 1995 a 2005, el paro y el deseo de lograr mejores condiciones laborales incitaron a nuevas generaciones instruidas a la migración: $15 \%$ de los jóvenes que habían concluido sus estudios universitarios abandonaron el país (Docquier y Marfouk, 2005), así como 23\% de los médicos y $15 \%$ de las enfermeras, que se dirigieron principalmente a Francia (Clemens y Pettersson, 2007). La emigración, como veremos, repercute también en los griots.

\section{La práctica de los griots y la inmigración}

Antes de la colonización, los djeli o griots aseguraban su sustento gracias a los nobles, a cuyos hijos educaban, y amenizando veladas en las que narraban cuentos y las hazañas de los ances- 
tros. Recordaban, además, en fiestas y reuniones, los méritos y las virtudes de su señor y los de sus antepasados. Sin embargo, en la actualidad, la mayor parte de ellos han debido adaptarse a las severas condiciones de los tiempos modernos.

Entre el djeli y el diatigui, ${ }^{5}$ su cliente noble, se establecía una particular relación de interdependencia, pues el primero participaba en todos los momentos importantes de la vida del segundo, como el nacimiento, la circuncisión, el matrimonio y el funeral. Mientras el noble necesitaba ser elogiado en público por sus actos y los de sus antepasados, el djeli recibía dones por ello. Hampâté Bâ (1982, p. 208) recuerda el proverbio que recomienda al noble ser prudente con el uso de la palabra porque ella es propiedad del djeli: "Hablar demasiado sienta mal a la boca de un horon". Este autor proporciona varios ejemplos que muestran esa particular conexión. Por ejemplo, el del djeli mediador que transmite a una joven el afecto o la admiración que siente por ella el pretendiente noble, o el de aquel griot que la víspera de la circuncisión anima al muchacho a mostrarse digno de sus antepasados durante la ceremonia: “Tu padre, que murió en el campo de batalla, se tragó 'las gachas [las balas] de hierro al rojo vivo' sin pestañear. Yo espero que mañana no tengas miedo del cuchillo cortante del herrero” (p. 209).

Entre las principales funciones de los griots bambara se encuentra la narración de relatos de géneros diversos como cuentos, leyendas e historias de las familias nobles, que instruyen a la vez que divierten; pero también la recitación de genealogías, la laudatio, el anuncio de noticias y la mediación (Montes, 2012, pp. 187-205). Para comprender dos de estas labores, la laudatio y la emisión de genealogías, resultan útiles algunos datos acerca del concepto del nombre de familia o dyamu, en bambara, y de la divisa, barama. El nombre (toko) designa el alma (ni) y su complementario (dya), es decir, la ascendencia paterna y materna de su portador, que lo particulariza entre otros individuos, pero que también indica su pertenencia a un grupo familiar (Dieterlen, 1988, p. 96). El apellido o dyamu, que procede del progenitor, está relacionado con un hecho histórico protagonizado por el ancestro y puede ser compartido con

${ }^{5}$ También conocidos como jàtigi. 
otros grupos de etnias diferentes. La atribución de un apellido no carece de importancia, ya que incluso está vinculado a las prohibiciones y los castigos, por ejemplo, los relativos al tótem.

De igual modo, la divisa familiar está estrechamente asociada al apellido. Cuando el djeli la emite, provoca un efecto llamativo en el individuo, resultado de un orgullo familiar que repercute también en el orador: "El trayecto efectuado en el interior del individuo que la oye, el efecto que le provoca y el que origina en el recitador se producen según un mecanismo conocido" (Dieterlen, 1988, p. 98). Las divisas aluden generalmente a hechos notables realizados por los antepasados. La genealogía o burudyu excita el ánimo del homenajeado, pues los honra a él y a su ascendencia, pero a la vez lo incita a imitar o superar las acciones de sus ancestros. El djeli y el noble alabado se nutren de este modo de la fuerza que origina la palabra. La recitación de la divisa y de la genealogía se produce en circunstancias diversas, como la imposición del nombre del recién nacido, las bodas, las ceremonias religiosas, las fiestas e incluso las asambleas.

Aquellos griots que gozan de mayor reconocimiento en la actualidad son los que más respetan la tradición y los que más conocimientos demuestran poseer. El saber que se valora principalmente es aquel que concierne a las costumbres de antaño, la historia de los pueblos y de las familias nobles, las composiciones literarias orales, la música y los ritos que constituían el bagaje cultural del pueblo y que se transmitían oralmente. Para producir admiración, el griot debe dar muestra de elocuencia, de modo que su discurso deleite, conmueva o persuada, según las circunstancias. Además, no puede manifestarse codicioso, por lo que conviene que nunca pida, sino que se conforme con los dones que sus diatigui le proporcionen.

Es fácil intuir que los nuevos tiempos no han facilitado el mantenimiento del código ético del griot, pues la pérdida de poder y de valor adquisitivo de las familias nobles, a medida que la colonización avanzaba, las desvinculaba de los djelis, ya que no podían hacer frente a sus gastos. Cuando los conocimientos tradicionales dejaron de asegurar el sustento de los maestros de la palabra, tuvieron que avivar su ingenio y buscar nuevas fuentes de ingresos. 
Un número importante de griots acudió a la música durante las independencias y las décadas posteriores y fusionó estilos musicales diversos; otros optaron por proferir elogios fáciles en eventos, aunque desconocían los orígenes de los elogiados, acto que iba en contra de los preceptos tradicionales, por lo que sufrieron el desprestigio popular (Sangaré, 2004a, p. 63; González, 2015 , p. 31); otro grupo, menor en número, continuó haciendo gala de su sabiduría, pero adaptándose a los nuevos tiempos, de modo que difundían las crónicas y las epopeyas en emisoras de radio. Algunos de ellos se convirtieron en portavoces de la revolución socialista de Modibo Keita y perpetuaron y reactualizaron a los héroes del pasado, a quienes comparaban con el nuevo presidente. Si los narradores populares, con su oratoria y su laúd, vinculaban la dinastía de Modibo Keita con el héroe épico Sundiata, su sustituto Moussa Traoré intentó igualmente enaltecer la historia de sus antepasados con la ayuda de la voz de los griots. La narración oral de las crónicas que gozaba de interés gracias a los medios de comunicación modernos pasó a ser así una excelente herramienta para los políticos y se convirtió en un ejemplo de la adaptación de los griots.

Aquellos griots que vivían en aldeas alternaban generalmente el ejercicio de su arte con otras labores, como el trabajo en el campo. Determinados pueblos se hicieron muy conocidos entre los investigadores que aspiraban a examinar la tradición, como Kéla, que se halla a cien kilómetros al suroeste de Bamako, porque los griots que allí viven protegen todavía con vigor las costumbres del pasado y especialmente la epopeya oral de Sundiata, el emperador mandinga ensalzado desde el siglo XIII.

En la década de 1960, muchos bambara habían puesto ya su mirada en otros países africanos y en Europa, sobre todo en las grandes urbes francesas. En los años setenta, no pocos de los que habían obtenido un puesto de trabajo en Francia consiguieron que sus esposas se reuniesen con ellos gracias a políticas de agrupamiento familiar. La emigración mandinga, de origen principalmente maliense, constituye una importante comunidad en París y en sus alrededores, y se congrega con frecuencia con motivo de ciertas ceremonias, como matrimonios, bautizos, funerales y la celebración del final del ramadán y del regreso de la peregrinación a La Meca (Derive, 2010, pp. 237-250). En 
la medida en que este colectivo desea preservar su identidad, otorga a los djeli gran protagonismo, desde el punto de vista tanto social como cultural. Algunos djeli ya habían llegado a Francia en los años sesenta y su intención no era otra que obtener un puesto de trabajo; sin embargo, la situación cambió a inicios de los años ochenta, pues la djeliya o jèliya, es decir el ejercicio profesional de los djeli, cobró mayor relevancia entre los inmigrantes mandinga. Algunos griots y griottes, ${ }^{6}$ que desarrollan esta labor social y cultural, están asentados en Francia alternando su cometido ancestral con un empleo en una empresa o en una fábrica, mientras que otros se desplazan del continente africano al europeo con motivo de determinadas celebraciones. En ocasiones, los miembros de la comunidad mandinga cotizan para pagarles el viaje a fin de que participen en encuentros en los que puedan elogiar a los allí reunidos.

Cuando los griots regresaban a su país, con sus comentarios acerca de los ingresos obtenidos en París propiciaban el desplazamiento de otros, que esperaban correr la misma suerte en la metrópoli. Derive (2010) defiende que el principal motivo de la llegada a la región parisina de un flujo migratorio de griots fue el éxito que conoció la música tradicional maliense en los años ochenta y noventa. Sus ingresos proceden, así, de dos fuentes: la laudatio y la música, que complace también a un público europeo. De este modo, el griot recuperó el reconocimiento popular que estaba perdiendo en su país de origen. Aunque se ajustan a los ritmos tradicionales, algunos intérpretes admiten haberlos adaptado ligeramente a los gustos del público más joven. A los temas y los motivos del pasado, añaden en sus cantos otros que se corresponden con las preocupaciones de la comunidad: el regreso al país natal o la nostalgia causada por la distancia, pero también el sida y el racismo. Los inmigrantes malienses constatan con complacencia el respeto que el intérprete manifiesta hacia los géneros tradicionales y les reconforta comprobar que tiene en cuenta sus sentimientos o sus preocupaciones.

Diferentes factores contribuyeron a la llegada de malienses a España. Aunque el principal motivo ha sido de índole econó-

${ }^{6}$ Griotte es el femenino de griot. También hallamos la grafía griote. 
mica, las carencias que afectan las condiciones de vida (salud, educación, etcétera) y los conflictos surgidos en el norte de Malí originaron también un movimiento migratorio importante. En los primeros años del siglo XxI, el número de malienses que llegó a España aumentó considerablemente. La embajada de España en Bamako comenzó a cumplir algunas de sus funciones en 2006, y la Oficina Técnica de Cooperación, dos años más tarde, en enero de 2008, fecha en la que se inauguró la embajada. Entre sus cometidos destaca la gestión del flujo migratorio de malienses hacia España, por lo que en enero de 2007 se firmó el Acuerdo Marco de Cooperación en materia migratoria entre el reino de España y la República de Malí (BOE-A-2008-9607). Mediante la Coordinadora de Organizaciones de Agricultores y Ganaderos se estableció un sistema de cuotas que permitía el desplazamiento de trabajadores temporeros agrícolas malienses a España, pero que con la crisis se redujo de manera llamativa. Como resultado de las relaciones bilaterales entre los dos países, el 29 de julio de 2009 el Consejo de Ministros de Malí decidió abrir embajada en Madrid.

En España, de acuerdo con los datos oficiales publicados por el Instituto Nacional de Estadística (2016b), el número de inmigrantes malienses ha disminuido notablemente desde 2008, como permite constatarlo el cuadro 1, muy probablemente como consecuencia de la crisis económica que sufre este país. Según la Encuesta de Población Activa de España (INE, 2016b), a finales de 2012 residían en España 24745 malienses, la mayor parte en Barcelona, Almería y Madrid. De acuerdo con la estadística del Padrón Continuo de INE (2018a), el 1 de enero de 2018 estaban censados en España 23685 malienses, de los cuales 19948 eran hombres y 3737 mujeres (503 hombres y 183 mujeres malienses en Toledo). También el flujo de inmigración procedente de Malí a la provincia de Toledo ha conocido una evidente disminución desde 2008, como se observa en el cuadro 2. La escasa presencia de población maliense en España en relación con Francia permite intuir que el número de griots que desarrollan sus actividades en territorio español es mucho menor. De hecho, asistir a conciertos en los que griots procedentes de África occidental deleiten con su voz y su arte musical es posible sólo en ocasiones. Mucho más 
difícil es escucharlos cantar en español. La mayor parte de los griots que viven en España y que obtienen ingresos gracias a sus actividades musicales las alternan muy frecuentemente con la agricultura u otra actividad laboral temporal. Reconocen que muchas de las funciones de sus antepasados han desaparecido de su cotidianidad y declaran que están orgullosos de pertenecer a esa casta.

CuAdro 1. Flujo de inmigración en España procedente de Malí, 2008-2017

\begin{tabular}{lrcc}
\hline Año & Hombres & Mujeres & Total \\
\hline 2008 & 3134 & 370 & 3504 \\
2009 & 1821 & 279 & 2099 \\
2010 & 1112 & 200 & 1312 \\
2011 & 850 & 237 & 1087 \\
2012 & 860 & 212 & 1072 \\
2013 & 994 & 168 & 1162 \\
2014 & 1045 & 200 & 1245 \\
2015 & 951 & 199 & 1150 \\
2016 & 912 & 253 & 1165 \\
2017 & 862 & 253 & 1115 \\
\hline
\end{tabular}

Fuente: elaboración propia con base en datos de la Estadística de migraciones del INE (2018b).

\section{Djeliba Souleymane y sus diatigui, una particular relación en Recas}

Djeliba Souleymane no vive en Recas durante la semana, sino únicamente desde la tarde del viernes a la del domingo, ya que su ocupación laboral no se lo permite. La empresa para la que trabaja se encuentra en la Comunidad de Madrid y se ocupa de cargar pollos y transportarlos a un matadero. El motivo que lo conduce a desplazarse a Recas cada fin de semana es estar en contacto con sus compatriotas malienses y la djeliya, a la que denomina "practicar".

Djeliba cree haber nacido el 18 de febrero de 1954, en la República de Guinea, donde su padre, maliense como su madre, 
CuAdro 2. Flujo de inmigración procedente de Malí a la provincia de Toledo, 2008-2017

\begin{tabular}{lc}
\hline Año & Total \\
\hline 2008 & 127 \\
2009 & 75 \\
2010 & 45 \\
2011 & 25 \\
2012 & 12 \\
2013 & 10 \\
2014 & 12 \\
2015 & 11 \\
2016 & 12 \\
2017 & 29 \\
\hline
\end{tabular}

Fuente: elaboración propia con base en datos de la Estadística de migraciones del INE (2018b).

trabajaba. Ésta es la fecha que le indicó su padre y que precisó a la autoridad competente para que constara en su partida de nacimiento. Sus progenitores pronto regresaron a Malí y se instalaron en Kayes, ${ }^{7}$ así que posee doble nacionalidad: maliense y guineana. Llegó a España en 1991, tras cruzar Marruecos. Después de vivir años en Cataluña, se estableció en la Comunidad de Madrid en 2011.

Souleymane procede de una familia de djeli. Está casado y tiene cinco hijos que residen en Malí. Su familia combina el trabajo agrícola con la djeliya. Al igual que otros muchos griots, aprendió a ejercerla en el entorno familiar, siguiendo principalmente el ejemplo de su padre y de sus tíos, aunque su madre participó asimismo en su educación de djeli. El griot en África occidental se forma inicialmente en el hogar, observando a su padre, aunque también a menudo los tíos del pequeño griot lo introducen en el medio tradicional. Desde sus primeros años aprende a tocar un instrumento musical, imitando a los mayores, y tiempo después los acompaña.

${ }^{7}$ Kayes es una ciudad que se encuentra a la orilla del río Senegal y es también la capital de la región que recibe el mismo nombre. Limita al norte con Mauritania, al oeste con Senegal, al este con la región maliense llamada Koulikoro y al sur con Guinea. 
La griotte presta especial atención a su madre y a sus tías; gracias a ella memoriza los cantos. La familia instruye de este modo a los más jóvenes. Además, pueden ampliar su formación en centros tradicionales, en los que otros eruditos maestros les ayudan a perfeccionar su arte y a adquirir nuevos conocimientos. Los investigadores coinciden en reconocer el protagonismo de los tíos en la enseñanza del griot. Afirman que son el padre y el tío los que orientan al principio el aprendizaje para ampliarlo posteriormente gracias a la ayuda de otros maestros (Kesteloot y Dieng, 1997, p. 55). También resaltan la función del tío materno en la enseñanza de la kora en el pasado (Camara, 1992, p. 133).

El escritor e historiador maliense Massa Makan Diabaté (1986, p. 115), descendiente de una familia de griots, señala que el joven, acompañando a su padre, memoriza relatos. A partir de los 14 años comienza a tocar un instrumento, y después un miembro de la familia le enseña su genealogía. Cuando cumple 21 años se independiza de la tutela de su padre y puede continuar su educación gracias a los conocimientos de otros griots más experimentados. Djeliba me explica que no vivir con sus hijos supone que no puede transmitirles ni los fundamentos de la djeliya ni los conocimientos que su padre le proporcionó, por lo que en cierto modo la inmigración ha interrumpido la costumbre familiar.

Djeliba afirma que pronto demostró interés por la djeliya y le hizo preguntas a su padre sobre el cumplimiento de sus actividades. La observación desempeñó una función esencial, pues él reparaba en el modo en que sus familiares mediaban para solucionar problemas y colaboraban en bodas y bautizos que se celebraban una semana después del nacimiento. Fijó así en su memoria, poco a poco, la historia de algunas familias. Asegura que los djeli malienses ejercen la djeliya al servicio de los miembros de las familias Traoré, Keïta o Kamara. En caso de disputa entre los componentes de estas ilustres familias, deben mediar para que haya un acuerdo. Su padre le contó la historia de sus antepasados, pero él le solicitó que le narrara también el origen de los apellidos Keïta y Traoré. Conoce también la historia del imperio mandinga, de Sundiata Keïta, el emperador de ese vasto territorio, y de Sogolon Diata, la madre del célebre 
monarca, pero el argumento de su narración presenta grandes diferencias respecto a las versiones publicadas.

Su padre tocaba el ngoni, pero él no. Su tía materna y sus tíos, tanto maternos como paternos, tocan instrumentos musicales. Ser djeliba no implica necesariamente ser músico, afirma Djeliba Souleymane (entrevista personal, 11 de abril de 2015), quien afirma: "De mi boca sale nuestra cultura". Aunque numerosos griots son músicos, una de las principales diferencias entre las dos grandes clases de griots malinké es la ausencia de práctica musical, pues mientras los jèlí son músicos y cantantes, los finá no tocan ningún instrumento musical (Camara, 1992, p. 125).

En el caso de Djeliba, la inmigración supuso pérdida de conocimientos musicales, ya que, confiesa, desde que abandonó Malí no ha producido música. La frecuente relación entre el griot y la música y las dificultades para subsistir han dado lugar al surgimiento de otro tipo de griots en África occidental que no han heredado la djeliya de sus padres y que se dedican a la canción o la música, conscientes de que si se hacen pasar por verdaderos griots gozarán de mayor reconocimiento social, a la vez que podrán mejorar su situación económica. Fatou Sangaré (2004a, p. 64) señala que, movida por la pobreza, la población emigra a las ciudades, lo que no siempre supone obtener un puesto de trabajo. Algunos individuos deciden ganar dinero con relativa facilidad eligiendo la música: "Esta nueva clase de djeli desconoce el significado de la función del auténtico djeli; su objetivo es ganar la mayor suma de dinero".

Cuando quise entrevistar a algunos griots que formaban parte de grupos musicales, muchos de ellos no manifestaron inconveniente en responder a mis preguntas, pero tras mi insistencia en que para entrevistarlos necesitaba que pertenecieran a familias de griots, el número de ellos se vio reducido en más de la mitad. También el djeli Habib Diabaté denuncia a estos falsos djeli producto de la miseria en Bamako: "Durante los matrimonios vemos hoy a personas de las que no sabemos si son djeli o si se han hecho djeli por las circunstancias, buscando una solución a la pobreza” (Sangaré, 2004c, p. 68).

Cada año, Djeliba Souleymane (entrevista personal, 11 de abril de 2015) disfruta de sus vacaciones en Malí y aprovecha su 
estancia allí para continuar su formación gracias a la ayuda de sus tíos paternos y de su madre. Su padre ya falleció. Asegura que les pregunta y que memoriza lo que le cuentan: "Ésa es la vida del djeliba".

En Recas ejercita la djeliya con sus compatriotas que proceden de la casta de los horon, como hacía su padre. Tiene las puertas abiertas de todos los hogares de los malienses de Recas, pues son sus diatigui. Sus funciones se centran principalmente en la mediación. Cuando surge un conflicto entre dos malienses, les recuerda su origen noble y busca una solución que dé fin a la disputa. Pero la mediación también incluye otros servicios, de modo que sus conciudadanos acuden a él para que ejerza de anfitrión en celebraciones, por ejemplo, en bodas y bautizos. Participa en más bautizos que en bodas porque el número de uniones en matrimonio es menor que el de nacimientos. Es él quien debe hablar en estos actos, tal como sucedía en el pasado, cuando el djeli era la voz del noble. Al menos una semana antes de que tenga lugar el evento, sus compatriotas solicitan su participación. Como saben que únicamente visita Recas los fines de semana, el festejo se produce obligatoriamente durante esos días.

Habib Diabaté ${ }^{8}$ explica a su entrevistador, Souleymane Sangaré, cómo colabora en Bamako en estas ceremonias, y a partir de ello constatamos que hay evidentes similitudes respecto a las funciones que desarrolla Djeliba en España:

Mi función en la sociedad permite que me ocupe de muchas cosas. Antes de los bautizos, debo prevenir al imán del barrio, encargarme de la compra de nueces de cola, informar a los padres, etcétera. Las gestiones de las bodas necesitan mayor prudencia porque algunas familias políticas expresan críticas falaces (Sangaré, 2004c, p. 67).

A cambio de los servicios cumplidos, Djeliba recibe dinero, ropa u otros objetos, al igual que ocurre en Malí. Insiste con rotundidad en que nunca pide algo a cambio por realizar estas funciones, sino que toma lo que le dan, ya que un auténtico

${ }^{8}$ Habib Diabaté nació en la región de Kayes, en un pueblo llamado Kougnakari. Cuando se produjo esta entrevista, tenía unos 53 años. El patronímico Diabaté revela su pertenencia a una de las más importantes familias de djeli. 
djeliba no pone precio a las prestaciones efectuadas. Me confiesa con satisfacción que, en una ocasión, uno de sus diatigui le regaló un billete de avión a Malí como compensación por la djeliya. Igualmente, en agosto de 2016, obtuvo 300 euros en una boda en Madrid, puesto que era el único djeli que estaba presente en la fiesta celebrada. Esa suma procedía de los dones de los invitados. Si otros djeli hubiesen asistido al evento, habría tenido que compartir el dinero. Recuerda que, tras la recolección, los diatigui entregaban a su abuelo incluso cinco sacos repletos de arroz o de maíz.

Aunque a menudo se dice que a los griots sólo los mueve el interés económico, son muchos los autores que defienden que no es así y atribuyen a los narradores el gran mérito de contribuir a preservar las culturas tradicionales africanas. Jansen (2001, p. 177) proporciona algunos ejemplos de djeli de Kéla que dieron muestra de una gran emoción al recibir regalos muy modestos. La mala reputación de un número importante de griots se origina en sus exigencias económicas y su avidez. Fatou Sangaré (2004a, pp. 64-65) apunta que son los primeros en llegar al ayuntamiento cuando se celebran bodas, y que en ocasiones son expulsados mientras son llamados parásitos. Informa que cuando asistió a la boda de una de sus primas en la región de Kayes, tuvo que gratificar económicamente no sólo a la djelimousso - griotte o mujer djeli-que ensalzó su ascendencia, sino a todos los djeli allí presentes. Una de las griottes rechazó el billete que le ofreció porque consideraba la suma muy modesta, teniendo en cuenta que Fatou Sangaré venía de Francia. Poco tienen que ver esos griots con los que se esmeraban por conocer la genealogía de sus diatigui, que protegían las tradiciones y que aceptaban de buen grado lo que les daban y les correspondía.

Cuando Djeliba está con sus diatigui, debe cumplir con sus obligaciones. Cada mañana acude a saludarlos y los acompaña si van a algún lugar. Se ofrece a realizar las compras que han de hacer. Otra de sus tareas es solicitar cotizaciones. Por ejemplo, cuando un maliense está enfermo y tiene que regresar a su país, pide a sus compatriotas de Recas que contribuyan para sufragar los gastos del billete de avión. Asimismo, con motivo de la celebración del Día de la Independencia de Malí, solicita a 
cada maliense que pague una cuota que facilite la organización de la fiesta.

En ocasiones acuden a este pueblo otros djeli, cuando sus trabajos como recolectores en diversas comunidades autónomas españolas se lo permiten. Si son más jóvenes que Djeliba y se aproxima algún evento que requiera coordinación de personas y medios, les indica las acciones que deben realizar.

Djeliba afirma que también recurre a la laudatio, pues en las celebraciones manifiesta en bambara su admiración por sus diatigui allí presentes, poniendo de relieve sus cualidades o sus virtudes, así como las de sus antepasados. El apellido o el nombre de clan del elogiado revela los méritos familiares, siempre y cuando el djeliba se haya instruido en su genealogía, ya que, como apunta Camara (1992, p. 29), el nombre de linaje "no es considerado únicamente como una marca de identidad, sino principalmente como un atributo honorífico para el portador". Si los antepasados han logrado perpetuar sus actos ilustres y señalados, es muy probable que el homenajeado haya seguido sus pasos. Cuando éste escucha las alabanzas del djeli, le entrega un don como signo de reconocimiento de su saber y su generosidad. El valor del regalo es mayor en función de las posibilidades económicas del donante, de su dadivosidad y de la oratoria del djeli. No se debe considerar el don como una retribución, sino como un derecho que tienen en ese sentido los artesanos, incluidos los de la palabra, sobre los nobles, que están obligados tradicionalmente a darles una recompensa (Hampâté Bâ, 1982, p. 210).

Según Djeliba, ser un buen djeliba exige informarse sobre la familia de sus diatigui, implicarse socialmente mediando y resolviendo conflictos, y respetar y aceptar las propuestas del diatigui. Afirma que aquellos djeli que juzgan con severidad la escasez de los dones que reciben no son buenos profesionales. Un auténtico djeliba debe aceptar lo que le den, agradeciendo el gesto del donante.

Asimismo, Djeliba manifiesta que está orgulloso de ser djeliba y menciona frecuentemente a su diatigui Amadou Traoré, que vive en Recas. Amadou llegó a España el 5 de mayo de 1990 y vive en este pueblo con su esposa y sus cuatro hijos. Espera algún día regresar definitivamente a Malí y vivir de la 
ganadería. Djeliba persiste en la satisfacción que le produce pertenecer a este grupo social, pero reconoce que no todos los djeli experimentan lo mismo. Con los nuevos tiempos han desaparecido las diferencias entre castas y, por consiguiente, no pocos perciben que ya no hay motivo para asistir a ningún individuo. Aunque Djeliba Souleymane (entrevista personal, 11 de abril de 2015) acepta la adaptación a las nuevas costumbres, muestra un gran apego a la tradición ancestral y a la djeliya: "Soy djeliba, nací djeliba y seguro que moriré djeliba".

Djeliba expresa sin pudor la superioridad del horon sobre el djeli; por ello, este último ha de mostrar respeto al noble. Cuando se encuentra en el hogar de Amadou, si éste desea tomar una infusión de té, Djeliba se la prepara. Pero Amadou también tiene obligaciones con Djeliba; por ejemplo, proporcionarle alimentos en caso de necesidad. Amadou me informa que, aunque el horon puede tener su propio djeliba, éste ha de estar al servicio de la comunidad. Amadou parece haberse adaptado a la modernidad con mayor facilidad que Djeliba y afirma no considerarse superior a él. Valora la importancia social del djeli y, para que yo la comprenda, me proporciona un sencillo ejemplo: una ceremonia sin djeliba no se desarrollará nunca del modo deseado, pues su presencia es esencial. Me indica que Djeliba conoce la historia de sus antepasados Traoré, pero no tan bien la historia personal suya (la de Amadou). Considera que la inmigración ha supuesto una ruptura con la tradicional relación entre el djeli y el diatigui, no sólo porque el primero rechace en ocasiones ejercer la djeliya en un país extranjero, sino también porque muchos boron se niegan a reconocerla, quizá porque son conscientes de que no pueden costear los gastos. El proverbio maliense que señala que una familia sin djeli es como un árbol sin hojas, y un djeli sin diatigui es como un huérfano, parece perder sentido (Sangaré, 2004b, p. 69). Djeliba no conocía a Amadou antes de su llegada a España, pero como su padre le había enseñado la divisa de los Traoré, al igual que la de otras familias, ha podido asociar ese apellido a la barama memorizada.

Muchos son los griots que prefieren que sus hijos no ejerzan la djeliya en las sociedades africanas ante el futuro incierto que dicho modo de vida les deparará (Mounkaila, 1989, p. 8). 
Convertirse en auténticos profesionales de la palabra exige una amplia formación y los nuevos tiempos no parecen reconocer el valor de tal esfuerzo.

Amadou, al igual que otros malienses que residen en Recas, respeta la tradición, cree que el presente se entiende conociendo el pasado, pero acepta con agrado la modernidad y algunos de los cambios que entraña; por ejemplo, la función de la mujer en la nueva sociedad.

\section{Conclusiones}

En África occidental, vivir de la djeliya presenta en la actualidad grandes dificultades, ya que las estructuras sociales resultantes de las colonizaciones, las independencias y los estados del siglo XXI exigen nuevas maneras de subsistir y han originado profundos cambios que afectan la tradición, fundamento del ejercicio profesional de los djeli. La existencia de cortes reales aseguraba el reconocimiento de la labor de los djeli y su pervivencia, pero la colonización asestó un duro golpe a un sistema social que había permanecido inmutable durante siglos y que parecía inquebrantable. En las últimas décadas, África pone cada vez más sus miras en modelos extranjeros totalmente alejados de los tradicionales.

El empobrecimiento de algunos países africanos y el afán de sus habitantes por encontrar otros modos de subsistencia han provocado el éxodo rural y la llegada de inmigrantes a las ciudades europeas. Recas ha sido polo de atracción de malienses debido a las oportunidades laborales que ha ofrecido durante años. En la actualidad es incluso lugar de encuentro de algunos malienses que no viven allí, pero que sienten que es su hogar en España junto con sus compatriotas. Djeliba es uno de ellos. Su desplazamiento semanal responde también a una realización personal. El cumplimiento de sus funciones mitiga el sentimiento de expatriación y la añoranza de la familia y de la tierra natal de sus diatigui, como Amadou Traoré, cuyo patronímico ya anuncia su origen horon. En Recas cumple con algunas funciones de las que la inmigración aún no ha prescindido, principalmente la mediación, pero no desarrolla, o lo hace en 
muy pocas ocasiones, otras tareas que exigen mayor conexión con la cultura original, como la narración de relatos orales tradicionales y la música. Quizá la razón por la que Djeliba se refiere a la djeliya como una práctica sea esta necesidad de uso continuo o ejercicio de un arte o facultad.

Por otra parte, los malienses de Recas reconocen el mérito de la labor de Djeliba, al valorar la importancia de la djeliya no sólo en la sociedad maliense tradicional y actual, sino también en el pueblo toledano donde residen. Djeliba y sus paisanos adaptan su relación a los nuevos tiempos y a su situación de inmigrantes. Amadou satisface las necesidades de Djeliba cuando es esencialmente necesario y este último lo asume y comprende. El respeto mutuo entre el djeli profesional, que se siente orgulloso de su pertenencia a este grupo social, y su diatigui debería garantizar el mantenimiento de un vínculo que surgió hace siglos, pero que es puesto en peligro por las dificultades que ambos han de superar en la actualidad.

Es muy posible que esta estrecha relación se transforme aún más en Europa y se debilite hasta extinguirse con el fin de las generaciones que nacieron en África y emigraron. Los hijos de los malienses que han nacido en España se forman en una sociedad muy diferente de aquella en la que se educaron sus progenitores, de modo que sería recomendable que se favoreciera el contacto entre ellos y esta valiosa figura de la tradición africana antes de que la distancia temporal y espacial les haga sentir que la presencia del djeli no es necesaria. Se evitaría, así, la pérdida de una parte fundamental de la identidad cultural de unos jóvenes españoles nacidos de padres malienses y se contribuiría a la protección de conocimientos milenarios que merecen ser salvaguardados y difundidos.

\section{Agradecimientos}

Deseo agradecer a Djeliba Souleymane sus explicaciones y su amabilidad, a Amadou Traoré sus informaciones y la agradable acogida en su hogar, y a Laura Fernández Díaz, alcaldesa de Recas, su atención y los datos aportados. 
Dirección institucional del autor:

Departamento de Filología Inglesa, Francesa y Alemana

Universidad de Oviedo

C/ Amparo Pedregal s./n.

33011 Oviedo, España

\section{Referencias}

Aвimbola, W. (1990). Décoloniser la pensée africaine. En Tradition et développement dans l'Afrique d'aujourd'hui (pp. 15-24). París: Unesco. Recuperado de https://unesdoc.unesco.org/ ark:/48223/pf0000086242_fre

Acuerdo marco de cooperación en materia de inmigración entre el Reino de España y la República de Mali. (4 de junio de 2008). Boletín Oficial del Estado, (135), 25633-25636. Recuperado de https://www.boe.es/diario_boe/txt.php?id=BOE-A-2008-9607

Ballo, M. (2009). Migration au Mali. Profil national 2009. Ginebra: Organisation internationale pour les migrations. Recuperado de https://publications.iom.int/system/files/pdf/mali_profile_2009.pdf

Banco Mundial. (2016). Tasa de incidencia de la pobreza, sobre la base de la línea de pobreza nacional (\% de la población). Washington: Banco Mundial. Recuperado de https://data.worldbank.org/ country/mali

Blit, T. (2009). "La tradition mandingue se tarit à la source". Entretien avec Vincent Zanetti, spécialiste des musiques d'Afrique de l'Ouest. Fragil.org. Recuperado de http://fragil.dreamhosters. $\mathrm{com} /$ focus/1219

Bouju, J. (1995). Tradition et identité. Enquête. Anthropologie, Histoire, Sociologie, (2), 95-117. Recuperado de https://journals. openedition.org/enquete/313

CAmara, S. (1992). Gens de la parole. Essai sur la condition et le rôle des griots dans la société malinké. París: Karthala.

Chamorro E., J. A. (1993). El papel de los Griots como cantores-historiantes y mediadores sociales. Relaciones, 14(53), 219239.

CHerIf, A. (2005). L'importance de la parole chez les Manding de Guinée : paroles de vie, paroles de mort et rituels funéraires. París: L'Harmattan.

Chevrier, J. (1990). Littérature nègre. París: A. Colin. 
Cissé, Y. T. y Kamissoko, W. (1988). La grande geste du Mali : des origines à la fondation de l'Empire. París: Karthala.

Clemens, M. y Pettersson, G. (2007). New data on African health professionals abroad. (Working Paper No. 95). Center for Global Development. Recuperado de https://www.cgdev.org/sites/ default/files/9267 file_CGDWP95_Feb_2007.pdf

Delafosse, M. (1912). Haut-Sénégal-Niger. París: Émile Larose.

Derive, J. (2010). Diaspora mandingue en région parisienne et identité culturelle. Productions de littérature orale en situation d'immigration. Journal des africanistes, 1-2(80), 237-250. Recuperado de https://journals.openedition.org/africanistes/2552

DerIVE, J. y Dumestre, G. (1999). Des hommes et des bêtes : chants des chasseurs mandingues. París: Association Classiques Africains.

Diabaté, M. M. (1986). Être griot aujourd'hui : entretien avec Massa Makan Diabaté. Notre Librairie, (75-76), 115-119.

DiARRA, S. et al. (1996). Enquête malienne sur les migrations et l'urbanisation (EMMU) 1992-1993: rapport national descriptif. Bamako: Centre d'études et de Recherche sur la Population pour le Développement.

Diarra, S. y Cissé, P. (2003). Migrations et pauvreté au Mali. En V. Hertrich y S. Keita (Eds.), Questions de population au Mali (pp. 203-226). Bamako: Le Figuier/Fonds des Nations Unies pour la population. Recuperado de https://www.ined.fr/Xtradocs/ CDRom_mali_population_change/Ouvrages/2003_Ouvrage\%20Māili/Mali_13_chap_9.pdf

Dieterlen, G. (1988). Essai sur la religion bambara. París: Presses Universitaires de France.

DOCQUIER, F. y Marfouk, A. (2005). International migration by educational attainment (1990-2000)-Release 1.1. International migration, remittances and development. Washington, D.C.: World Bank. Recuperado de https://perso.uclouvain.be/frederic.docquier/ filePDF/DM_ozdenschiff.pdf

GonzÁlez G.-M., F. J. (2015). El griot no ha muerto, viva el hiphop. Philologica Canariensia, 21, 25-44. http://dx.doi.org/10. 20420/PhilCan.2015.0033

Hampâté BÂ, A. (1972). Aspects de la civilisation africaine. París: Présence Africaine.

Hampâté BÂ, A. (1982). La tradición viviente. En J. Ki-Zerbo (Dir.), Historia general de África. Vol. I: Metodología y prehistoria africana (pp. 185-222). Madrid: Tecnos.

Instituto Nacional de Estadística (INE). (2016a). Cifras oficiales de población resultantes de la revisión del patrón municipal a 1 de 
enero. Madrid: INE. Recuperado de http://www.ine.es/jaxi/ Datos.htm?path =/t20/e244/avance/p02/10/\&file =1 mun00.px Instituto Nacional de Estadística. (2016b). Encuesta de Población Activa (EPA). Tercer trimestre de 2012. Madrid: INE. Recuperado de https://epa.com.es/padron/malienses-en-espana/

Instituto Nacional de Estadística. (2018a). Estadística de migraciones del INE. Madrid: INE. Recuperado de https://www.ine.es/dyngs/ INEbase/es/operacion.htm?c $=$ Estadistica_C\&cid $=1254736177$ 000\&menu $=$ ultiDatos\&idp $=1254735573002$

Instituto Nacional de Estadística. (2018b). Estadística del Padrón Continuo. Madrid: INE. Recuperado de http://www.ine.es/jaxi/ Datos.htm?path =/t20/e245/p04/provi/10/\&file =0ccaa002.px Jansen, J. (2001). Épopée, histoire, société. Le cas de Soundjata, Mali et Guinée. París: Karthala.

Kesteloot, L. (1993). L'épopée bambara de Ségou (T. 1). París: L'Harmattan.

Kesteloot, L. y Dieng, B. (1997). Les épopées d'Afrique noire. París: Unesco-Karthala.

Ministère de l'Environnement et de l'Assainissement. (2011). Seconde communication nationale du Mali sur les changements climatiques. United Nations Developmet Programme-Global Environment Facility. Recuperado de https://unfccc.int/resource/ $\mathrm{docs} / \mathrm{natc} / \mathrm{mlinc} 2 . \mathrm{pdf}$

Montes N., V. E. (2012). Los griots: de bardos protectores a narradores desprotegidos. Anales de Filología Francesa, 20, 187-205.

Mounkaila, F. (1989). Le mythe et l'histoire dans la geste de Zabarkane. Niamey: Centre d'etudes linguistiques et historiques par tradition orale.

Organización Internacional para las Migraciones. (2013). La crise au Mali sous l'angle de la migration. Recuperado de https://www. iom.int/files/live/sites/iom/files/What-We-Do/docs/Mal_Migration_Crisis_June\%202013_FR.pdf

PÂQues, V. (2005). Les Bambara. París: L'Harmattan.

Programa de las Naciones Unidas para el Desarrollo (PNUD). (2016). Informe sobre Desarrollo Humano 2016. Recuperado de http:// hdr.undp.org/sites/default/files/HDR2016_SP_Overview_ Web.pdf

Sangaré, F. (2004a). Griots et griottes : de Bamako à Paris. Africultures, (61), 62-65. Recuperado de http://africultures.com/ griots-et-griottes-de-bamako-a-paris-3622/

SANGARÉ, F. (2004b). Mah Damba, djelimusso nyuma, la sublime griotte. Africultures, (61), 69-71. Recuperado de http://africul- 
tures.com/mah-damba-djelimusso-nyuma-la-sublime-griotte3624/

SANGARÉ, S. (2004c). Habib Diabaté, griot et fier de l'être. Entretien de Souleymane Sangaré avec Habib Diabaté. Africultures, (61), 66-68. Recuperado de http://africultures.com/habib-diabategriot-et-fier-de-letre-3623/

Seydou, Ch. (Ed. y trad.). (1976). La geste de Ham-Bodêdio ou Hama le Rouge. París: A. Colin. 